Novinsky, M, Nesensohn, C., Ihwas N., and Haghsheno, S. (2018). "Combined Application of Earned Value Management and Last Planner System in Construction Projects." In: Proc. $26^{\text {th }}$ Annual Conference of the International. Group for Lean Construction (IGLC), González, V.A. (ed.), Chennai, India, pp. 775-785. DOI: doi.org/10.24928/2018/0491. Available at: www.iglc.net.

\title{
COMBINED APPLICATION OF EARNED VALUE MANAGEMENT AND LAST PLANNER SYSTEM IN CONSTRUCTION PROJECTS
}

\author{
Mark Novinsky ${ }^{1}$, Claus Nesensohn ${ }^{2},{\text { Nadia } \text { Ihwas }^{3} \text { and Shervin Haghsheno }}^{4}$
}

\begin{abstract}
The application of the Last Planner System (LPS)in the construction industry is increasing more and more. Reviews in the literature report that by applying LPS project performance is improving. However practical experience shows that there is some lack of structure in daily work. Further more researchers are still looking for feasible process measurement.

This paper aims to contribute to the described challenge by developing a concept for the combined application of the two following methods. One is Earned Value Management (EVM), a project control method that combines data regarding scope, schedule, and resources to assess project performance and progress. The other one is LPS, a Lean Construction method for production planning and control. In LPS project workflow is developed and controlled collaboratively within a team. Through the combined application of these two methods based on the structure and a transparent production plan the project's workflow can be measured by objective metrics like Percent Plan Complete (PPC), Schedule Variance (SV) and Cost Variance (CV) to highlight the need for potentially necessary corrective action.
\end{abstract}

\section{KEYWORDS}

Lean construction, last planner system, earned value management, process measurement, work structuring.

1 M.Sc. Student. Karlsruhe Institute of Technology (KIT), Institute of Technology and Management in Construction, Gotthard-Franz-Str. 3 (Am Fasanengarten), Geb. 50.31, D-76131 Karlsruhe, Germany. Phone +49(0)17634151483, mark@ novinsky.de

2 Founder \& CEO. Refine Projects AG, Schelmenwasenstraße 34, D-70567 Stuttgart, Germany. Phone +49 (0) 179978 9624, claus.nesensohn@ refineprojects.com.

3 Research Fellow. Karlsruhe Institute of Technology (KIT), Institute of Technology and Management in Construction, Gotthard-Franz-Str. 3 (Am Fasanengarten), Geb. 50.31, D-76131 Karlsruhe, Germany. Phone +49 (0) 721608 45476, nadia.ihwas@ kit.edu.

4 Professor. Karlsruhe Institute of Technology (KIT), Institute of Technology and Management in Construction, Gotthard-Franz-Str. 3 (Am Fasanengarten), Geb. 50.31, D-76131 Karlsruhe, Germany. Phone +49(0)721 608 42646, shervin.haghsheno@ kit.edu. 


\section{INTRODUCTION}

In many construction projects a lack of project structure and the fact that project progress regarding cost and schedule efficiency is not measured are major challenges. Due to lack of transparency for stakeholders during the design and construction process, deviations from the planned process are not forecasted and measurement of deviations is often taken into account too late.

Tools and methods already exist which both facilitate structuring projects and measuring their progress. Such methods are e.g. Earned Value Management (EVM) and the Last Planner System (LPS)(Ballard 2000), a Lean Construction method. The two methods differ in their application and their output: Whereas EVM allows to measure project progress and project efficiency by specific key figures focusing on schedule and cost, LPS fosters collaboration of all participants and process reliability is measured by key figures like the Percent Planned Complete (PPC). The joint application of the two methods can result in a holistic system for the measurement of project progress considering both economic aspects and process quality in terms of collaboration and quality of workflow. Both a more transparent and effective progress measurement and a better project structure can be achieved.

The combined application of EVM and LPS and the potential benefits for construction projects have been analysed by only a few studies so far. This paper will provide a detailed analysis of the impact of the combined application of EVM and LPS on construction projects as a whole and on their process quality in particular, on a theoretical basis. Results of this paper shall provide a solid ground for further analyses and case studies.

\section{THEORETICAL FOUNDATIONS OF EVM AND LPS}

EVM is a project control system that enables the measurement of project progress and project efficiency. In a first step, the project is structured into work packages by creating a Work Breakdown Structure (WBS). Secondly, an earnings plan is derived and finally, project progress is measured by comparing the earnings plan with the actual work accomplished(Project Management Institute (PMI) 2008).EVM was developed by industrial engineers of the US Department of Defense (Fleming and Koppelman 2010).

In order to measure project progress, specific key figures (Table 1) are collected during the project and are gradually analysed(PMI 2008). Relevant key figures are explained in 
Table 1: Key metrics of EVM (based on PMI 2008)

\begin{tabular}{|c|c|c|}
\hline Metrics & $\begin{array}{c}\text { Alternative } \\
\text { designations }\end{array}$ & Interpretation \\
\hline $\begin{array}{l}\text { Planned } \\
\text { Value = PV }\end{array}$ & $\begin{array}{l}\text { Budgeted Cost of Work } \\
\text { Scheduled = BCWS }\end{array}$ & $\begin{array}{l}\text { Indicates how much work should be done to date. } \\
\text { Actual project progress is measured against the PV. }\end{array}$ \\
\hline $\begin{array}{l}\text { Earned } \\
\text { Value }=E V\end{array}$ & $\begin{array}{l}\text { Budgeted Cost of Work } \\
\text { Performed = BCWP }\end{array}$ & $\begin{array}{l}\text { The value of work performed expressed in terms of } \\
\text { the approved budget assigned to that work. }\end{array}$ \\
\hline $\begin{array}{l}\text { Actual Cost } \\
\quad=A C\end{array}$ & $\begin{array}{l}\text { Actual Cost of Work } \\
\text { Performed }=\text { ACWP }\end{array}$ & $\begin{array}{l}\text { Are the total costs that have actually incurred in a } \\
\text { given time to accomplish a certain amount of work. }\end{array}$ \\
\hline
\end{tabular}

Since control systems focus on metrics that are most relevant for the success of the respective projects (Sumara and Goodpasture 1997), EVM aims to provide an integrated cost/schedule progress monitoring system(Fleming and Koppelman 2010). Therefore, two variances are derived from the key figures shown above in order to measure project progress accordingly (Cândido et al. 2014). In general, variances measure deviations from planned values and their corresponding indices allow to compare the performance of different projects(PMI 2008). Relevant variances and indices are shown in Table 2.

Table 2: Variances and Indices of EVM (based on PMI 2008)

\begin{tabular}{|c|c|c|}
\hline Variance or Index & Formula & Interpretation \\
\hline Scheduled Variance = SV & $S V=E V-P V$ & Measures deviations from schedule \\
\hline $\begin{array}{l}\text { Schedule Performance } \\
\text { Index = SPI }\end{array}$ & $\mathrm{SPI}=\mathrm{EV} / \mathrm{PV}$ & $\begin{array}{l}\text { Indicates overall time efficiency and how } \\
\text { efficient time is used by the project team. }\end{array}$ \\
\hline Cost Variance $=\mathrm{CV}$ & $C V=E V-A C$ & Measures deviations from budget \\
\hline $\begin{array}{c}\text { Cost Performance Index } \\
=\mathrm{CPI}\end{array}$ & $\mathrm{CPI}=\mathrm{EV} / \mathrm{AC}$ & $\begin{array}{l}\text { Indicates overall cost efficiency and how } \\
\text { efficient financial resources are used }\end{array}$ \\
\hline
\end{tabular}

EVM is typically applied based on the Critical Path Method (CPM) that supports the push system, whereas the LPS supports the pull system. In the developed model the metrics of the EVM are used, but the pull system of the LPS is applied.

LPS was developed by Ballard and Howell and is currently the most common method in Lean Construction (Mossman 2015). Lean Construction is the transfer of Lean Thinking, which is based on the philosophy of Lean Production and the Toyota Production System, to the construction industry: The construction project shall be delivered through maximizing customer value and eliminating waste during production(Ballard 2000).

During their extensive research Ballard and Howell found out that these objectives are achieved if production is based on a high-quality commitment-based planning system (Ballard and Howell 1998). For this purpose LPS was developed. The Last Planners within LPS are those project participants who actually realize the planned work on site (e.g. sub-contractors, craftsmen etc.) (Ballard and Howell 1994). Within LPS, they jointly 
plan their work based on a pull system and make their own commitments(Mossman 2015).

During weekly meetings, the Last Planners measure the reliability of their commitments with the key figure Percent Plan Complete (PPC) (Ballard 2000). PPC is "attained by dividing the number of completed assignments by the total number of assignments each week" (Ballard and Howell 1998). Hence causes for deviations are discovered and discussed among the Last Planners. Based on these findings they are able to respond appropriately to difficulties and to improve their processes (Ballard 2000). Other metrics like Task Made Ready (TMR) and Task Anticipated (TA) are also used to analyse the planning process (Hamzeh et al. 2016) but are not focused for this model.

The LPS basically divides a project into four main planning levels. Per each level, the degree of detail increases.(Ballard 2000; Hamzeh et al. 2008; Mossman 2015; and others). Those four levels are also the basis for the designed model and are shown in Figure .

\section{RESEARCH METHODOLOGY}

This research is based on a combination of a systematic literature review, which established the context of the current state-of-the-art regarding EVM and LPS in a combined application within the construction industry, and an empirical study, which made use of experts (Arriagada and Alarcón C 2014) to provide a more fundamental understanding of the combined use of EVM and LPS.

Therefore a case study driven research with two rounds of semi structured interviews took place. This is a strong and flexible method to understand the experience of individuals(Fontana and Frey 1994). They also enhance the depth and breadth of the phenomenon under investigation, having been seen to be particular useful for research within the construction sector(Shehu and Akintoye 2010).

The case study project is the design phase of a new build pharmaceutical production plant with a project volume of 215 million $€$ in which EVM and LPS were jointly implemented. Both rounds of interviews utilised a purposive sampling to select the relevant participants(Bryman 2012). The interviewees of the first round have been four experts with professional experience of the use of EVM within the construction industry as project manager or consultant. Each interview was conducted with a standardised interview guide which was pre-tested to ensure quality(Fontana and Frey 1994) and suitability of the allocated interview time (Häder 2015; Schnell 2012). The guidelines were sent in advance to the interviewees for preparation. The advantage of this approach is the flexibility in asking potential questions which are outside the guideline. This enables to explore the knowledge of the participants in depth. The interviews lasted approximately 60 minutes and were tape-recorded and transcribed afterwards. These transcripts have been analysed using a systematic approach called the "framework approach"(Ritchie and Lewis 2003).

Based on the literature research, experience from observations during the case study and a first round of interviews a model for implementing the combination of EVM and LPS in design was developed. The second round of interviews was used to ensure validity 
by so-called member checks. For this purpose the experts involved in the data collection of the original research were interviewed to ensure the interpretation of the data was accurate.

\section{MODEL AND IMPLEMENTATION CONCEPT}

Based on the first findings of the research, an abstract model for the combined application of EVM and LPS was developed as shown in Figure 1. The model consists of four workshops equal to the four planning levels of the LPS.

EVM

\begin{tabular}{|c|c|c|}
\hline - Cost Assumption & $\begin{array}{c}\text { 1st Level } \\
\text { WBS }\end{array}$ & $\begin{array}{c}1 \text { st } \\
\text { Workshop } \\
\end{array}$ \\
\hline $\begin{array}{l}\text { - Definition of work packages } \\
\text { - Cost Calculation }\end{array}$ & $\begin{array}{c}\text { 2nd Level } \\
\text { WBS }\end{array}$ & $\begin{array}{c}\text { 2nd } \\
\text { Workshop } \\
\end{array}$ \\
\hline & & $\begin{array}{c}\text { 3rd } \\
\text { Workshop }\end{array}$ \\
\hline $\begin{array}{l}\text { Variances: CV , SV } \\
\text { - Performance Indices: } \\
\text { CPI, SPI }\end{array}$ & Evaluation & $\begin{array}{l}\text { 4th } \\
\text { Workshop }\end{array}$ \\
\hline
\end{tabular}

LPS

\begin{tabular}{|c|c|}
\hline Master Plan & $\begin{array}{l}\text { - Identification of phases / project } \\
\text { steps to achieve project end }\end{array}$ \\
\hline Phase Plan & $\begin{array}{l}\text { - Refinement into week packages } \\
\text { Definition of milestones }\end{array}$ \\
\hline \begin{tabular}{|c|l|}
\hline Lookahead \\
Plan
\end{tabular} & $\begin{array}{l}\text { - Production planning on daily } \\
\text { basis by day processes } \\
\text { - Reliable commitments }\end{array}$ \\
\hline $\begin{array}{c}\text { Weekly work } \\
\text { planning }\end{array}$ & $\begin{array}{l}\text { - Evaluation of last week } \\
\text { - Recuted activities }=>\text { PPC }\end{array}$ \\
\hline
\end{tabular}

Figure 1: Abstract model of the combination of EVM and LPS

A concept was derived from the model to implement both methods in a project. In the following section the implementation process is explained by the example of a design project.

\section{FIRST WORKSHOP: MASTER PLAN}

In the first workshop, representatives of all disciplines collaboratively define the objectives that should be achieved at the end of the project. As shown in Figure 1, the relevant phases are identified on the first level of planning. The phases are planned backwards beginning with the project's end from right to left and they identify the relevant tasks that have to be completed in order to achieve the project's objectives(Ballard and Howell 2003).

In the next step the phases are broken down in process steps to define which disciplines are involved. At this level a rough planning of quantities is conducted without consideration of time aspects. Based on this a first cost assumption by the stakeholders is made, generating a first Planned Value. Additionally, the expected workload can be roughly assessed at a very early stage of the project. 

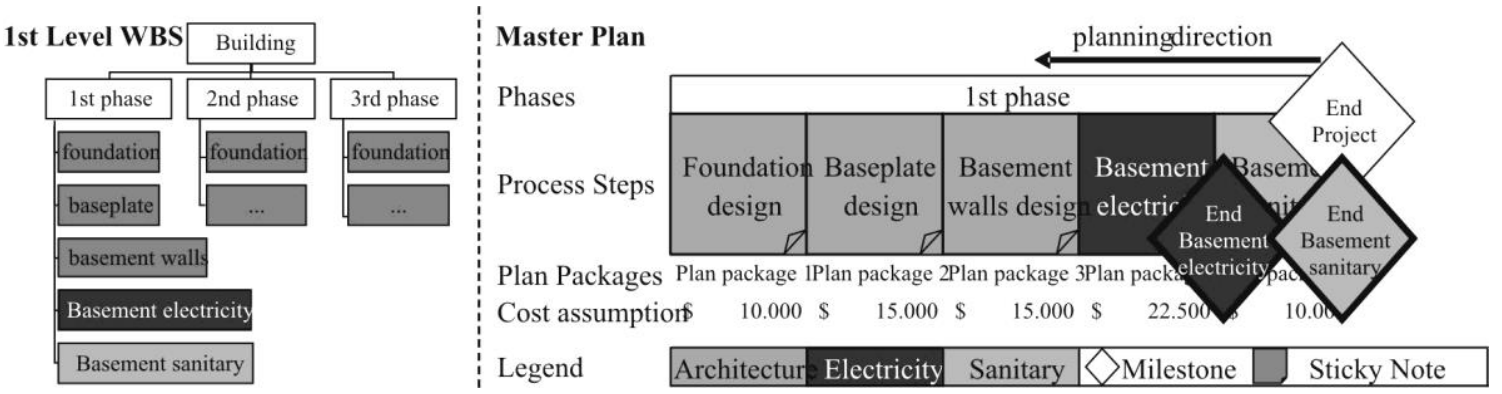

Figure 1: WBS and Masterplan with Plan Packages and process milestones

The end of every process step is marked by a milestone which, by adding a budget, turns into a budget milestone (framed by black line).By assigning coloured sticky notes to each discipline a better visual overview is achieved. The Master Plan must have a 1:1 relation to the WBS to guarantee a clear project structure and hierarchical order of the work packages to measure physical process (Emblemsvåg 2014).

\section{SECOND WORKSHOP: PHASE PLAN}

During the second workshop, a phase plan is developed in order to further refine the WBS and to arrange the process steps of the master plan in a suitable time sequence(Ballard and Howell 2003). As shown in Figure 2: WBS and Phase planning with Quality Gates

the process steps are divided by discipline into Week Packages and added to a timeline of project weeks. To guarantee a clear structure, elements on the higher level must be completely explained by lower elements.

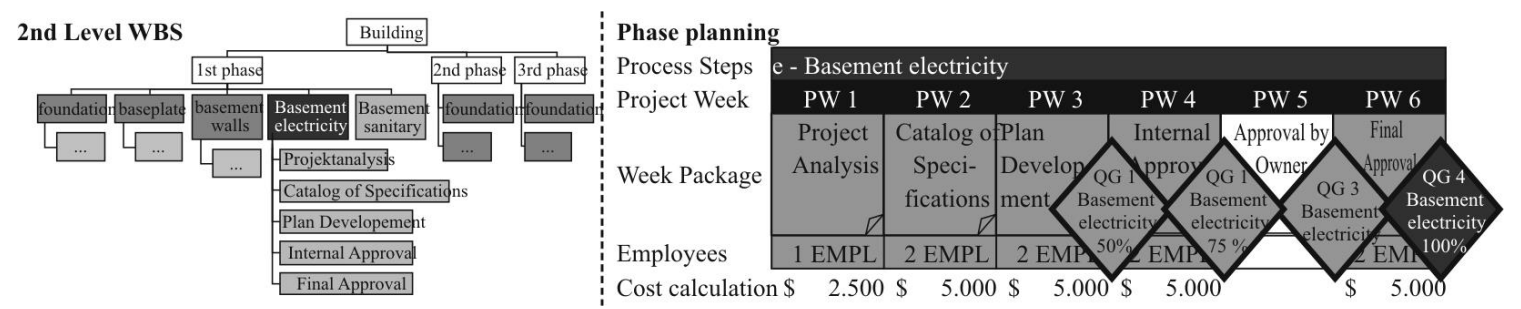

Figure 2: WBS and Phase planning with Quality Gates

During the design phase of a project processes usually last for a longer period. Therefore so-called Quality Gates (QG) are defined. They equal intermediate milestones defining a specific status of the plan package e.g.: (1) Document created, (2) Document internally approved, (3) Document released by owner, (4) Document finally released.

Based on the expected overall workload of a plan package, a share of the expected workload respectively of the available budget is assigned to each QG. Consequently, a process step is completed by $100 \%$ if the last precondition of a QG is met.

At this level the resource planning is conducted by assigning the number of employees to a work package. By adding the budget milestones to the Phase Plan a first baseline is created being a precondition for the Planned Value. 


\section{THIRD WORKSHOP: LOOK AHEAD PLAN}

In the Look ahead Plan the processes planned on a weekly basis are broken down into Daily Processes. This can be realized by sticky notes on a planning board in a central meeting room. In the example as shown in Figure 3: Productionplanning in the Lookahead Plan with Quality Gates fifteen commitments are necessary to achieve the black-framed QG 1 . In the $1^{\text {st }}$ project week there are 5 commitments. The Planned Value of this week is 5/15 commitments, which are budgeted by 33,3\% of the budget of completion of the QG 1. In the case that the number of employees is varying, the Budget At Completion (BAC) is divided by the total number of employees and multiplied by the number of employees per week to get the weekly budget. While establishing the look ahead plan, it was discovered that for achieving the planned work packages additional employees are necessary compared to the phase plan.

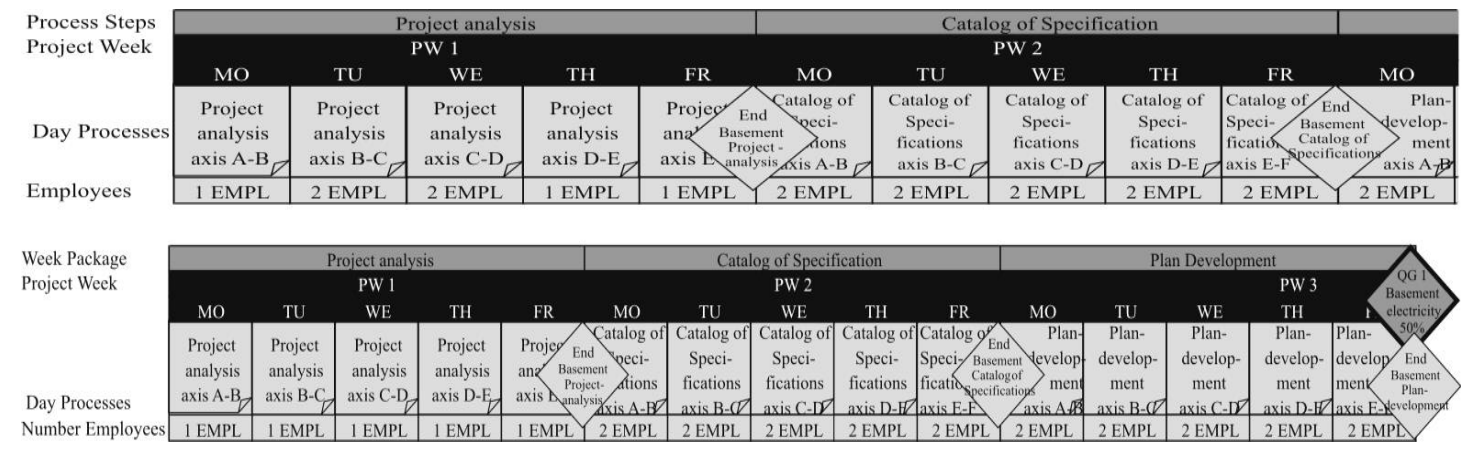

Figure 3: Productionplanning in the Lookahead Plan with Quality Gates

\section{FOURTH WORKSHOP: EVALUATION}

In a weekly meeting the past week is evaluated. Therefore, it is measured which of the planned activities have been completed. By the ratio of the planned and completed activities the key figure PPC is calculated(Ballard 2000). In Figure 4 it is shown that three out of five activities are executed, leading to a PPC of $60 \%$.

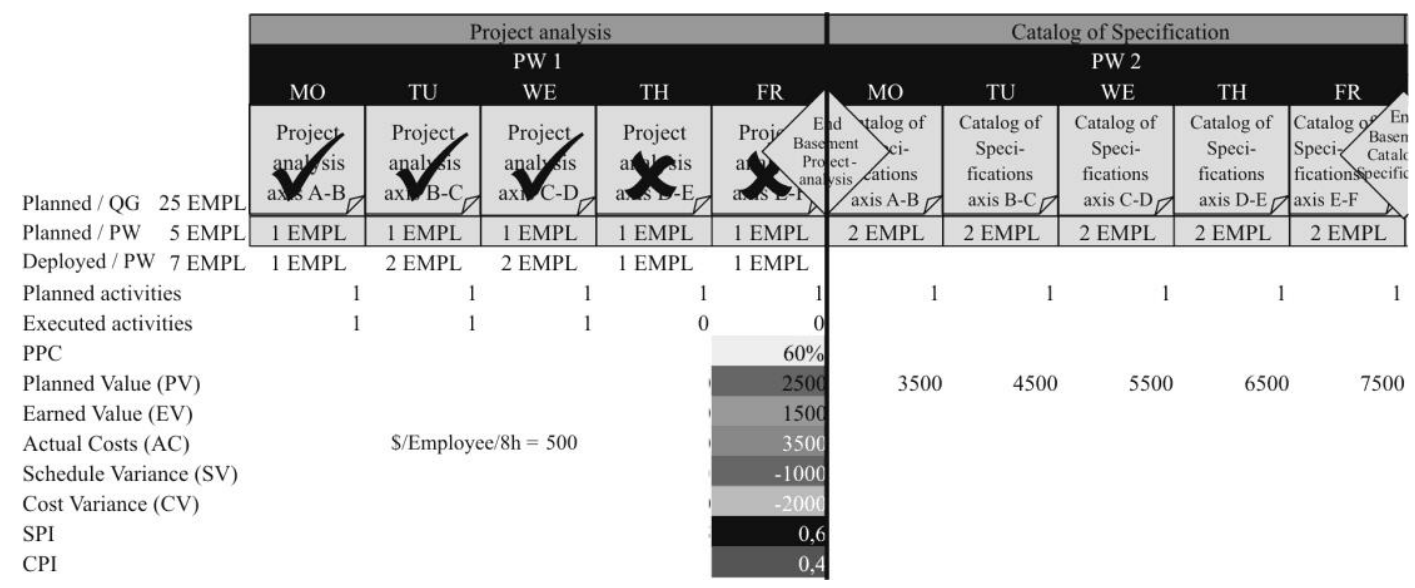

Figure 4: Evaluation of the Lookahead Plan with calculations of the EVM 
The Planned Value with regard to the Phase Plan was at 2500 \$. With the PPC of $60 \%$ we get to an Earned Value of 1500 \$. By the difference of EV and PV a negative SV-value is calculated indicating that the project is behind schedule.

In the phase plan, the need for five employees was assumed. But the lookahead plan had revealed, that actually seven employees were needed. With a calculation of $500 \$$ per employee per day costs of $3500 \$$ were generated. The difference of EV and AC results in a negative $\mathrm{CV}$. With the calculated numbers we obtain the efficiency indicators SPI of 0,6 and CPI of 0,4 as shown in Figure 5.

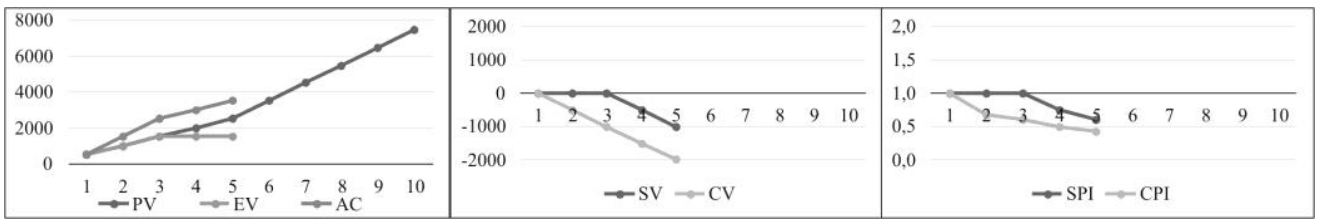

Figure 5: The measures of the EVM after the first project week

With these numbers the project team receives a good impression of their performance, not only regarding their planning reliability but also with respect to the parameters Schedule and Cost. By receiving a nearly alarm signal in the case of variances, countermeasures can be initiated properly.

After the evaluation of the past week the upcoming week is revised in the Lookahead Plan. As shown in Figure 6the unfinished daily processes are rescheduled. If processes have not yet been monitored, these processes are also added to the original workload. Therefore, it must be evaluated if those additional processes can be realized together with the originally planned workload as shown or if the entire process step needs to be shifted to the future together with the budget milestone. The same case occurs if tasks are added that have not been planned yet. Since at the time of budgeting the whole budget was already allocated this leads to additional costs. Figure 7 displays that with the additional employees the SV of the first week was caught up, demonstrated by the SV line going towards 0 . But with the additional costs the CV line is following a downward tendency.

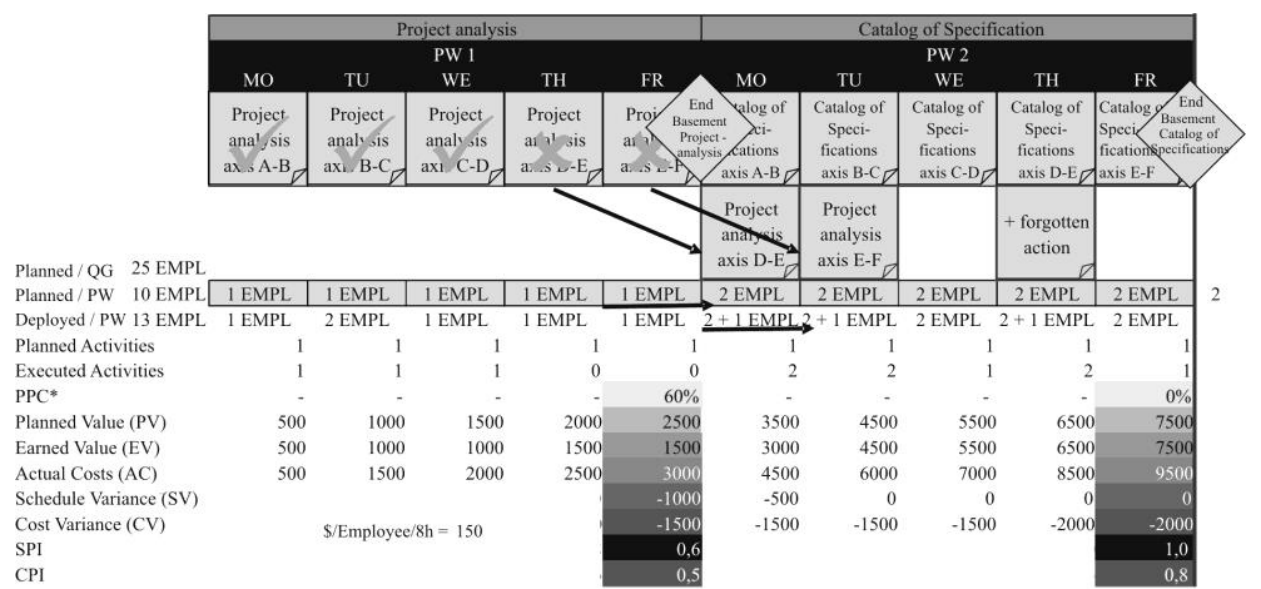

Figure 6: Production planning of the $2^{\text {nd }}$ project week after the evaluation with rescheduling of the not fulfilled commitments 


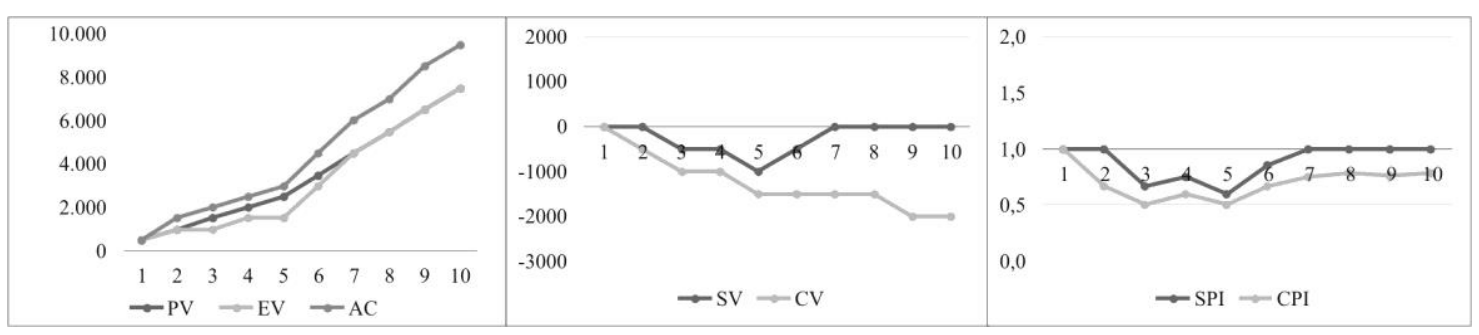

Figure 7: The measures of the EVM after the second PW

\section{VALIDATION}

Through the second round of expert interviews the potential of the concept was evaluated. EVM practitioners, not being familiar with LPS, expressed that they see great value due to the fact that a detailed production planning is implemented. They are getting a more transparent and less subjectively planned process and a greater reliability of the numbers.

Additional reasons for variances can be extinguished on an early state and facilitate the team to implement early countermeasures. LPS practitioners see in the concept a good chance of eliminating the lack of process measurement. By using the system, the cost estimations can be evaluated and a learning process for further projects is being applied.

Despite the mentioned advantages it is questionable, whether the concept can be implemented in an analogue system like LPS which is currently often used. By using sticky notes for production planning there is no automated alignment to a cost account system. With further research towards the digitalisation of LPS a high potential could possibly be generated. Additionally, different opinions were stated regarding the question, up to which level the WBS should be graduated. In bigger projects a level of detail of one week might be sufficient, whereas in smaller projects the tracking of daily tasks can be reasonable.

\section{CONCLUSION}

Both EVM and LPS are project control systems, but both systems focus on distinct aspects. LPS focuses on the measurement and optimization of workflow. With LPS the reasons for deficiencies are becoming more transparent. But cost or schedule performance in particular are not directly measured. Nevertheless both factors are of great interest for the customer to have an idea of the current status of the project. Therefore EVM could complement LPS since it focuses on measuring and controlling project progress with regard to schedule and especially costs. Consequently, the joint application of EVM and LPS could lead to a holistic progress measurement of a project considering both quantifiable metrics like schedule and costs but also factors like quality of work flow and collaboration. Analyses in this paper have shown that the combination of both systems offers indeed high potential to improve both process quality and performance of construction projects.

In this paper, a concept for implementing a combined control system of LPS and EVM was devolved in a design project but based on the survey there is no limitation for the implementation in construction projects as well. Key aspects of both methods were 
combined, and the concept was developed and finalized on basis of a case study and expert interviews. The case study revealed that a long pre-planning phase is required to implement the suggested concept. Companies, which decide to implement both EVM and LPS, need to establish a strong standard that supports the application of this concept. To achieve this, not only commitment of the Last Planners is required, but also commitment of the management is essential for the successful implementation.

Additionally, expert interviews revealed that the measurement of the Earned Value is getting more objective by the transparent production planning of the Last Planner. Nevertheless, without the support of IT Systems the data collection for performance measurement will end up in time consuming processes, which may impede the implementation. Ponz-Tienda et al. 2015 developed a model that can serve as a basis for further analyses.

If standards are properly set and processes are controlled regularly, the joint application of EVM and LPS can lead to better project performance. Since the concept was developed and validated within the design phase, a further case study or action research within projects with both design and construction phase would be beneficial. All in all the developed concept offers a sound basis in order to initiate the next steps.

\section{REFERENCES}

Arriagada, R. E., and Alarcón C, L. F. (2014). "Quantification of Productivity Changes Due to Work Schedule Changes in Construction Projects: A Case Study." Revista de la Construcción, 9-14.

Ballard, G., and Howell, G. (1994). "Implementing lean construction: Stabilizing work flow." Lean construction, 101-110.

Ballard, G., and Howell, G. (1998). "Shielding Production: Essential Step in Production Control." Journal of Construction Engineering and Management, 11-17.

Ballard, G., and Howell, G. A. (2003). "An Update on Last Planner." 11th Annual Conference of the International Group for Lean Construction, 22-24.

Ballard, H. G. (2000). The last planner system of production control, University of Birmingham.

Bryman, A. (2012). Social research methods, Oxford Univ. Press, Oxford u.a.

Cândido, L. F., MählmannHeineck, L. F., and Barros Neto, José de Paula (2014). Critical analysis on earned value management (EVM) technique in building construction, Oslow, Norway, 2014.

Emblemsvåg, J. (2014). "Lean project planning: Using lean principles in project planning." International Journal of Construction Project Management, 6(2).

Fleming, Q. W., and Koppelman, J. M. (2010). Earned value project management, Project Management Institute, Newtown Square, Pa.

Fontana, A., and Frey, J. H. (1994). "Interviewing: The Art of Science." The Handbook of Qualitative Research, N. Denzin and Y. Lincoln, ed., Thousand Oaks: Sage Publications, 361-376.

Hamzeh, F., Zankoul, E., and Sakka, F. E. (2016). "Removing Constraints to Make Tasks Ready in Weekly Work Planning." Procedia Engineering, 68-74. 
Hamzeh, F. R., Ballard, G., Tommelein, I. D., Tzortzopoulos, P., and Kagioglou, M. (2008). "Improving Construction Work Flow - The Connective Role of Lookahead Planning." 16th Annual Conference of the International Group for Lean Construction. Mossman, A. (2015). Last Planner $®: ~ 5+1$ crucial \& collaborative conversations for predictable design \& construction delivery <http://bit.ly/LPS-5cc > (20.08.17).

Ponz-Tienda, J. L., Pellicer, E., Alarcón3, L. F., Rojas-Quintero, J. S., Seppänen, O., González, V. A., and Arroyo, P. (2015). "Integrating Task Fragmentation and Earned Value Method Into the Last Planner System Using Spreadsheets." 25th Annual Conference of the International Group for Lean Construction, 63-71.

Project Management Institute (PMI) (2008). A guide to the project management body of knowledge (PMBOK guide), Project Management Institute, Newtown Square, Pa.

Ritchie, J., and Lewis, J., eds. (2003). Qualitative research practice: A guide for social science students and researchers, Sage, London u.a.

Shehu, Z., and Akintoye, A. (2010). "Major challenges to the successful implementation and practice of programme management in the construction environment: A critical analysis." International Journal of Project Management, 26-39.

Sumara, J., and Goodpasture, J. (1997). "Earned Value - The Next Generation - A Practical Application for Commercial Projects." Project Management Institute 28th Annual Seminars \& Symposium Chicago, Illinois, 13-17. 